\title{
Meta
}

Journal des traducteurs

Translators' Journal

\section{FRANJIÉ, Lynne, dir. (2016): Guerre et traduction. Représenter et traduire la guerre. París: L'Harmattan, 225 p.}

\section{Gertrudis Payàs}

Volume 63, numéro 1, avril 2018

URI : https://id.erudit.org/iderudit/1050524ar

DOI : https://doi.org/10.7202/1050524ar

Aller au sommaire du numéro

Éditeur(s)

Les Presses de l’Université de Montréal

ISSN

0026-0452 (imprimé)

1492-1421 (numérique)

Découvrir la revue

Citer ce compte rendu

Payàs, G. (2018). Compte rendu de [FRANJIÉ, Lynne, dir. (2016): Guerre et traduction. Représenter et traduire la guerre. París: L'Harmattan, 225 p.] Meta, 63(1), 253-254. https://doi.org/10.7202/1050524ar

Ce document est protégé par la loi sur le droit d'auteur. L'utilisation des services d'Érudit (y compris la reproduction) est assujettie à sa politique d'utilisation que vous pouvez consulter en ligne.

https://apropos.erudit.org/fr/usagers/politique-dutilisation/
Cet article est diffusé et préservé par Érudit.

Érudit est un consortium interuniversitaire sans but lucratif composé de l’Université de Montréal, l'Université Laval et l'Université du Québec à Montréal. Il a pour mission la promotion et la valorisation de la recherche. https://www.erudit.org/fr/ 


\section{DOCUMENTATION}

\section{Comptes rendus}

FranjIÉ, Lynne, dir. (2016): Guerre et traduction. Représenter et traduire la guerre. París: L'Harmattan, 225 p.

En su brevísima introducción, la autora Lynne Franjié señala como objetivo llenar un vacío en los estudios de traducción en lengua francesa (todos los trabajos de la compilación, salvo uno, están escritos en francés) en lo que toca a dos preguntas que se plantean en el estudio de la traducción en tiempos de guerra: la primera es si puede el traductor sustraerse a las circunstancias de los conflictos para ejercer su labor ideal de facilitador del diálogo y la segunda es como comprender un ejercicio de la traducción que no sea promotor de la paz y la tolerancia, o que lo sea solo sobre el papel. Se parte, pues, del ideal del traductor como puente, un ideal que se encuentra obviamente impugnado, o al menos bastante problematizado en las situaciones de guerra.

Este tercer volumen de la colección Traductologie está conformado por once trabajos, además de la introducción y conclusión de la directora de la edición. Fuera de un artículo (La traduction comme préalable à la guerre), que se sitúa en la sección introductoria, los demás se distribuyen en cuatro secciones: Traduire la seconde guerre mondiale, Traduire les guerres de l'Europe de l'Est, Traduire la guerre des Balkans des années 1990, Traduire les guerres du Moyen-Orient, y, finalmente, Traduire les organisations internationales. La organización por contextos geopolíticos es útil en la medida en que permite leer juntos trabajos relativos a una misma experiencia temporal, pero puede resultar menos interesante para quienes buscan comprender mejor las prácticas, independientemente de los contextos.

El trabajo introductorio de Ons Debbech, inspirado en la obra de Said y el estudio de las representaciones exóticas de la mujer oriental, ilustra el papel de las traducciones en la constitución de los climas previos a los conflictos. En el apartado dedicado a la segunda guerra mundial, Laurent Gallardo expone con interés las ambivalencias, zonas grises y tensiones en las prácticas de interpretación en los campos de concentración nazis. Poder y resistencia son las palabras clave del análisis de las distintas figuras del traductor que se evidencian en las memorias noveladas del recluso catalán Amat-Piniella. También sobre los campos de concentración escribe Fleur Kuhn-Kennedy, desmenuzando las operaciones de traducción mental del entrevistador ${ }^{1}$ como traductor/intérprete, que hacen inteligible los testimonios de los supervivientes. Particularmente interesante es su discusión sobre el archivo oral y la dimensión colaborativa y conflictiva de su construcción.

Las guerras de Europa del Este son el objeto de un segundo apartado, que comienza con el estudio (Ekaterina Eremina) de las traducciones al ruso de algunos autores de la Beat Generation en el periodo de la Guerra Fría. Desde la perspectiva de la manipulación (Lefevere), la autora describe como fueron seleccionados ciertos autores, mientras que otros fueron directamente marginados. De los seleccionados: Ginsberg, Kerouac, sus obras fueron al mismo tiempo censuradas e intervenidas para inscribirse en el discurso oficial soviético, acentuando los aspectos de crítica al capitalismo. El artículo de Tatar Andelic sobre sus propias traducciones al francés de artículos de actualidad del periódico Monitor, de Montenegro, aporta una perspectiva personal, de reflexión ética y política en el contexto del final de la guerra de los Balcanes y la disolución de la antigua Yugoeslavia. Informar sobre los conflictos internacionales es una de las tareas encomendadas a la traducción; el trabajo siguiente, de Nikol Dziub, sobre el reciente conflicto entre Ucrania y Rusia pone de manifiesto como las guerras y conflictos inciden en las condiciones de ejercicio de los oficios de las lenguas, y como la traducción puede ser instrumentalizada, a escalas diversas (palabra, concepto, discurso, metadiscurso) para fines políticos al reproducir o hacerse eco de la retórica del conflicto.

El tercer apartado comporta dos trabajos dedicados a los conflictos de Oriente Medio, marcados por los acontecimientos que siguieron a los ataques del 11 de septiembre de 2001. La cuestión de la lengua y los intérpretes en lo que se ha llamado la cuarta guerra de Afganistan (2001-2014) se aborda en el trabajo de Blanchet, que introduce el tema desde la historia de las derrotas inglesas en territorio afgano y la construcción discursiva de un sujeto afgano violento y bárbaro, fuera de toda ley. El compromiso británico con la contrainsurrección otorga un papel fundamental a la comunicación interlingüística; de ahí la importancia de los intérpretes, que se hacen a la vez imprescindibles y sospechosos de traición. Igualmente interesante es el artículo siguiente, de Balsam Mustafa, sobre la resemantización del concepto árabe sabi (toma 
de cautivos, sobre todo mujeres, del enemigo), según lo ha empleado el llamado Estado Islámico, y su traducción en los distintos medios árabes y occidentales. Se pone aquí de manifiesto cómo la traducción actúa modificando las narrativas ideológicas subyacentes a las palabras. La relación entre traducción y medios de comunicación en la era digital, con su potencial de diseminación y diversificación, es uno de los ejes de este trabajo.

Finalmente, la traducción en los organismos internacionales es el tema de los dos últimos trabajos del volumen. Corina Veleanu se interesa por el concepto de "responsabilidad de proteger", un concepto que se encuentra, como dice, en la encrucijada de mitos y arquetipos, y su traducción en el marco de los conflictos armados y diplomáticos de nuestro tiempo. Su artículo se centra en el uso de las metáforas empleadas para definir los conceptos clave que pueden justificar propagandísticamente una intervención. En el último trabajo (Hanaa Beldjerd) se cuestiona el derecho internacional como productor de significados obtenidos por negociación diplomática, que no tienen raigambre cultural y que por lo tanto se traducen a nivel meramente lingüístico en las lenguas oficiales de las Naciones Unidas. Como resultado de ello, al trasladarse a las legislaciones nacionales se produce un desfase comunicativo. La prioridad estriba en la coincidencia a nivel de los tratados, y la traducción a las lenguas oficiales refuerza así el aspecto diplomático de los textos, es decir, una cierta vaguedad, que contribuye al mantenimiento de las relaciones de poder.

Pese a estar en todos los trabajos profundamente problematizada, la conclusión de la compiladora insiste, con cierta ingenuidad, a juicio nuestro, en una visión idealista de la traducción. Vistos en conjunto, los trabajos, por lo general bien fundamentados y de indudable interés, muestran ante todo la heterogeneidad de funciones, modalidades, soportes mediáticos y contextos del ejercicio de los oficios de las lenguas (traducción, interpretación, terminología), con los dilemas ético-políticos y profesionales que plantean. De esta heterogeneidad, más que una lección de lo que debe hacer el buen traductor, debería surgir con fuerza, creo, el llamado a una urgente reflexividad crítica sobre nuestro quehacer.

Gertrudis PayÀs Universidad Católica de Temuco, Temuco, Chile

\section{NOTAS}

1. Boder, David P. (1949): I Did Not Interview the Dead. Urbana: University of Illinois Press.
GÉmAR, Jean-Claude et Ho-Thuy, Vo (2016) : Nouvelles difficultés du langage du droit au Canada. Montréal: Thémis, 658 p.

Les rapports entre le droit et son langage sont des plus intimes. C'est cette symbiose qui est au cœur de la jurilinguistique. Le contact quotidien entre le français et l'anglais, et la cohabitation de la common law et du droit civil facilitent un «extraordinaire processus d'échange jurilinguistique au Canada» (p. XIV). Cette dualité linguistique et juridique, source de richesse et d'inspiration, peut aussi soulever des difficultés. Ces difficultés sont relevées dans cette publication à la fois savante et ludique ${ }^{1}$. Quelque 240 entrées y sont présentées «selon un schéma classique: position du problème, avec terme en contexte dans une ou plusieurs citations; présentation étymologique et historique du terme; analyse notionnelle et linguistique du terme. Une brève conclusion présente, à l'occasion, des recommandations. Le terme ou l'expression présentés sont le plus souvent assortis de considérations historiques, philologiques, voire littéraires ou anecdotiques» (p. XIX).

Suivant la terminologie utilisée dans ce texte, on peut proposer le classement suivant des difficultés répertoriées:

Anglicismes: banc; confession; être à l'emploi de; être imputable; technicalité; etc.

Archaïsmes: amalgamation; bref; confession; forger; etc.

Impropriétés: fardeau; être à l'emploi de; etc. Barbarismes $^{2}$ : amalgamation; céduler; cihaut; terme d'office (le statut de terme de référence, par contre, est moins tranché); prendre une action; mépris de cour;

Régionalismes: assermentation; plaidoyer; etc.

Faux synonymes: acheteur c. acquéreur; action collective c. recours collectif; délictuel c. délictueux; plaidoyer c. plaidoirie; valide c. valable; force majeure et cas fortuit (interchangeables dans presque tous les contextes, par contre); etc.

Pléonasmes: accommodement raisonnable; période de probation; impenses ou dépenses somptuaires (voir voluptuaire); montant total; etc.

Néologismes: action collective;

Solécismes: plaider coupable;

Termes intraduisibles parce qu'ils appartiennent à un autre système juridique (voir Common law et Equity);

Fautes de style: majuscules; être à l'emploi de; etc.

Ce classement comprend des catégories qui ne sont pas exclusives les unes des autres. Un seul 